\title{
Transcatheter valve interventions: playground for cardiologists or cardiac surgeons? The cardiologist's view
}

\author{
Antonio Colombo ${ }^{1,2 *}$, MD; Neil Ruparelia ${ }^{1,2,3}$, DPhil, MRCP \\ 1. San Raffaele Scientific Institute, Milan, Italy; 2. EMO-GVM, Centro Cuore Columbus, Milan, Italy; 3. Imperial College, \\ London, United Kingdom
}

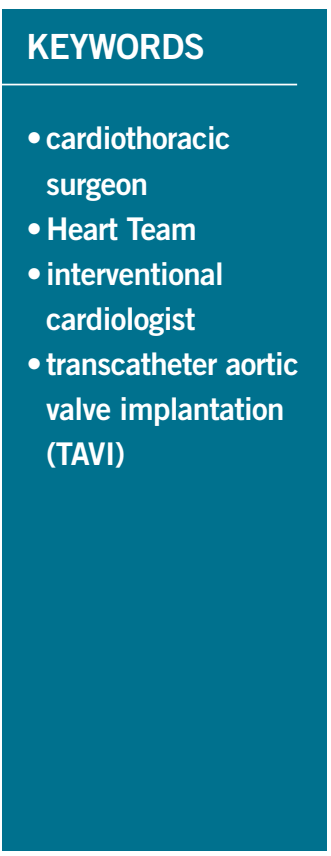

\begin{abstract}
Historically, the only interventional management option for valve pathology was cardiac surgery. However, the rapid evolution of transcatheter valve interventions has catapulted cardiologists into a central role in the management of these patients. A welcome consequence of this rapid change in the landscape has been the fostering of new and improved relationships between cardiologists and cardiac surgeons and the formulation of "Heart Teams" to facilitate patient management. We believe that the cardiologist, who already utilises many of the clinical and procedural skills required to manage this complex group of patients, is optimally placed to be the central figure within the multidisciplinary team, and to deliver these treatments with the ultimate aim of achieving the best possible patient outcomes.
\end{abstract}

\footnotetext{
*Corresponding author: EMO-GVM Centro Cuore Columbus, Via Buonarroti 48, 20145 Milan, Italy. E-mail:info@emocolumbus.it
} 


\section{Introduction}

The last few years have witnessed rapid advances in transcatheter valve therapies, predominantly with regard to the treatment of aortic valve degeneration but also, more recently, in the fields of mitral $^{1}$ and tricuspid intervention ${ }^{2}$.

The treatment of severe symptomatic aortic stenosis (AS) has historically been firmly in the realm of cardiac surgeons and surgical aortic valve replacement (SAVR) the "gold standard" treatment option for all patients. The advent and widespread adoption of transcatheter aortic valve implantation (TAVI) has now resulted in it becoming the treatment option of choice for patients deemed to be inoperable or of prohibitively high surgical risk ${ }^{3}$. Continued refinements in TAVI prosthesis design coupled with excellent medium- and longterm outcomes ${ }^{4,5}$ are likely to make this the default treatment option for this patient group in the near future. The expansion of the field is now addressing a wider range of conditions, including severe aortic regurgitation associated with moderate aortic stenosis and valve-invalve procedures for surgical bioprosthetic valve failure.

\section{TAVI or SAVR: who will make the decision?}

A possible algorithm for the future management of elderly patients presenting with symptomatic AS regardless of surgical risk is illustrated in Figure 1. TAVI would become the default treatment option with SAVR the default option only if the Heart Team predicts that the TAVI result will not be optimal. What criteria would be used to predict suboptimal TAVI outcome? Possible scenarios are as follows: a) predicted high incidence of moderate or severe paravalvular leak due to unfavourable anatomy (extreme calcification, some subsets of bicuspid valve, ideal size of transcatheter valve unavailable); b) suboptimal femoral access requiring more invasive approach (e.g., transapical, transaortic) - in this situation, the relative risk-benefit ratios of SAVR and the more invasive transcatheter approach need to be compared; c) risk of stroke due to aortic arch atheroma - this situation may potentially be overcome by use of filter protection of the carotid circulation and the SAVR

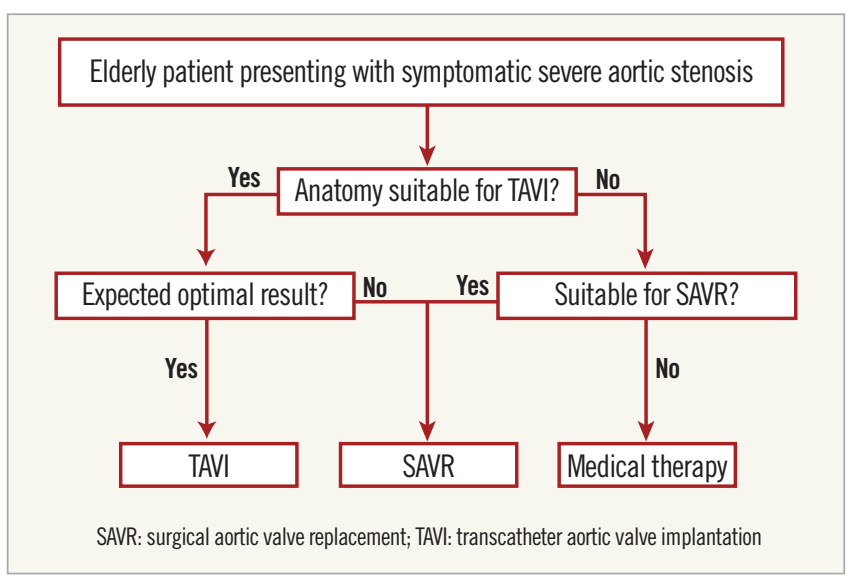

Figure 1. Proposed algorithm to assist in decision making for the management of elderly patients with severe symptomatic aortic stenosis. alternative may not necessarily be safer; d) risk of coronary artery occlusion due to low origin of the coronary ostia; e) high risk of complete heart block in a patient in whom permanent pacemaker implantation would be poorly tolerated or undesirable; f) need to treat other coexisting conditions requiring cardiac surgery (e.g., mitral regurgitation unsuitable for percutaneous management or coronary artery disease with a high SYNTAX score).

The next question therefore is who will perform the necessary clinical evaluation? Answer - the Heart Team! Without any doubt, the combined expertise of interventional cardiologists, cardiac surgeons, imaging cardiologists, cardiac anaesthetists and general physicians (in conjunction with the patient's wishes) is critical in reaching the correct management decision.

\section{Who will perform TAVI as the principal operator?}

TAVI procedures are now virtually completely "percutaneous" and general anaesthesia (GA) is no longer mandatory. The transfemoral route is the default approach for vascular access in the majority of procedures due to its associated advantages ${ }^{6}$ without requirement for general anaesthesia and surgical exposure of the femoral artery. In our view, the interventional cardiologist already possesses the required skills, including the handling of guidewires and catheters and image selection, and is familiar with likely complications (e.g., coronary obstruction, cardiac tamponade), and is therefore best qualified to act as the principal operator. Attempts should be made to perform TAVI via a transfemoral approach where possible since the transapical approach is associated with inferior outcome ${ }^{7}$. Balloon dilatation of the iliofemoral vessels or use of a dedicated balloonexpandable sheath (SoloPath ${ }^{\circledR}$; Terumo, Somerset, NJ, USA) should be considered when transfemoral access is suboptimal.

However, the role of the surgeon is by no means obsolete! Not all complications can be managed percutaneously and a cardiac surgeon and vascular surgeon need to be readily available (and familiar with individual cases and their technical aspects) for the rare event when surgical intervention is the only viable rescue option (Table 1). Furthermore, the cardiac surgeon has the skills to ensure procedural success in patients where an alternative more invasive vascular access route is preferable and should be the principal operator whilst the interventional cardiologist adopts a supportive role.

Regardless of vascular access route, the imaging cardiologist is essential in guiding valve interventions. Moreover, the cardiac anaesthetist has a vitally important role in the management of potentially rapidly changing haemodynamics in patients who are usually elderly with multiple comorbidities. The concept of "team work" (as opposed to "solo operator") is therefore key.

\section{Conscious sedation or general anaesthesia?}

The first TAVI procedures were performed under conscious sedation (CS) but were followed by a move towards use of GA due to the belief that periprocedural transoesophageal (TEE) monitoring was essential. With greater operator experience and improvements in the design of current TAVI devices, we believe (and it is our current practice) that most TAVI procedures can be performed 
Table 1. Potential complications of TAVI and their management.

Complication

Vascular complication

Cardiac tamponade

Aortic root rupture

Coronary obstruction

Conduction disturbance
First-line treatment option

Second-line treatment option

Percutaneous treatment with prolonged contralateral balloon inflation or stent/covered stent implantation

Percutaneous drainage

Surgical repair

Percutaneous coronary intervention

Permanent pacemaker implantation

Extracorporeal circulation should be readily available to support the patient while more definite treatment is instituted. safely with CS alone, provided that anaesthetic support is readily available to convert to GA if required. The presence of an expert echocardiographer who is able to perform immediate transthoracic echocardiography (or TEE if required) is vital in the early recognition of complications. Rapid pathways to deal with emergencies should also be established (e.g., cardiac surgery suite/hybrid room, extracorporeal circulation, vascular surgery).

\section{Post-procedural care}

Post-procedural care (e.g., initiation and titration of medical therapy) and rehabilitation are critically important in optimising functional status and clinical outcomes ${ }^{8}$. Whilst the input of several different medical specialties may be important here (especially in the presence of multiple comorbidities), we believe that the cardiologist again has the leading and central role to play by virtue of familiarity with all aspects of general cardiology (e.g., heart failure and arrhythmia management), something which is commonly required in the management of these complex patients.

\section{Conclusion}

In conclusion, we are of the opinion that the cardiologist is best placed to take a lead in the overall management of the majority of patients undergoing transcatheter valve interventions, albeit in the context of an overall "Heart Team" approach. We strongly believe that the expertise of all relevant specialties (not just cardiologists or cardiac surgeons) is invaluable in facilitating optimal patient selection, procedural planning, complication management, postprocedural care and optimised patient outcomes.

\section{Conflict of interest statement}

A. Colombo is a minor shareholder in Direct Flow Medical. N. Ruparelia has no conflicts of interest to declare.

\section{References}

1. Maisano F, Alfieri O, Banai S, Buchbinder M, Colombo A, Falk V, Feldman T, Franzen O, Herrmann H, Kar S, Kuck KH, Lutter G, Mack M, Nickenig G, Piazza N, Reisman M, Ruiz CE, Schofer J, Sondergaard L, Stone GW, Taramasso M, Thomas M, Vahanian A, Webb J, Windecker S, Leon MB. The future of transcatheter mitral valve interventions: competitive or complementary role of repair vs. replacement? Eur Heart J. 2015;36:1651-9.

2. O’Neill WW, O'Neill BP. Transcatheter tricuspid valve intervention: the next frontier. $J$ Am Coll Cardiol. 2015;65:1196-8.
3. Joint Task Force on the Management of Valvular Heart Disease of the European Society of Cardiology (ESC), European Association for Cardio-Thoracic Surgery (EACTS), Vahanian A, Alfieri O, Andreotti F, Antunes MJ, Baron-Esquivias G, Baumgartner H, Borger MA, Carrel TP, De Bonis M, Evangelista A, Falk V, Iung B, Lancellotti P, Pierard L, Price S, Schafers HJ, Schuler G, Stepinska J, Swedberg K, Takkenberg J, Von Oppell UO, Windecker S, Zamorano JL, Zembala M. Guidelines on the management of valvular heart disease (version 2012). Eur Heart J. 2012;33:2451-96.

4. Mack MJ, Leon MB, Smith CR, Miller DC, Moses JW, Tuzcu EM, Webb JG, Douglas PS, Anderson WN, Blackstone EH, Kodali SK, Makkar RR, Fontana GP, Kapadia S, Bavaria J, Hahn RT, Thourani VH, Babaliaros V, Pichard A, Herrmann HC, Brown DL, Williams M, Akin J, Davidson MJ, Svensson LG; PARTNER 1 trial investigators. 5-year outcomes of transcatheter aortic valve replacement or surgical aortic valve replacement for high surgical risk patients with aortic stenosis (PARTNER 1): a randomised controlled trial. Lancet. 2015;385:2477-84.

5. Kapadia SR, Leon MB, Makkar RR, Tuzcu EM, Svensson LG, Kodali S, Webb JG, Mack MJ, Douglas PS, Thourani VH, Babaliaros VC, Herrmann HC, Szeto WY, Pichard AD, Williams MR, Fontana GP, Miller DC, Anderson WN, Akin JJ, Davidson MJ, Smith CR; PARTNER trial investigators. 5-year outcomes of transcatheter aortic valve replacement compared with standard treatment for patients with inoperable aortic stenosis (PARTNER 1): a randomised controlled trial. Lancet. 2015;385:2485-91.

6. Stortecky S, O'Sullivan CJ, Buellesfeld L, Windecker S, Wenaweser P. Transcatheter aortic valve implantation: the transfemoral access route is the default access. EuroIntervention. 2013;9 Suppl:S14-8.

7. Blackstone EH, Suri RM, Rajeswaran J, Babaliaros V, Douglas PS, Fearon WF, Miller DC, Hahn RT, Kapadia S, Kirtane AJ, Kodali SK, Mack M, Szeto WY, Thourani VH, Tuzcu EM, Williams MR, Akin JJ, Leon MB, Svensson LG. Propensity-matched comparisons of clinical outcomes after transapical or transfemoral transcatheter aortic valve replacement: a placement of aortic transcatheter valves (PARTNER)-I trial substudy. Circulation. 2015;131:1989-2000.

8. Zanettini R, Gatto G, Mori I, Pozzoni MB, Pelenghi S, Martinelli L, Klugmann S. Cardiac rehabilitation and mid-term follow-up after transcatheter aortic valve implantation. $J$ Geriatr Cardiol. 2014;11:279-85. 